by the further isolated current pulses which began to occur. In practice, the liquid was conditioned up to $100 \mathrm{kV} . / \mathrm{cm}$. or so beyond the maximum stress used during the measurements.

A series of conductivity curves for several gapdistances in the range $300-50 \mu$ have been obtained. These tests show that:

(i) Once conditioning has been carried out for one polarity, no further conditioning is necessary for measurements of the other polarity.

(ii) For symmetrical electrodes with a spacing of about $75 \mu$ there is no polarity effect, and identical conductivity graphs were obtained for stresses up to $1,150 \mathrm{kV} . / \mathrm{cm}$.

(iii) For electrodes of different metals, the conductivity curve depends on the nature of the cathode; for example, using chromium and silver for the electrodes, the current for $1,000 \mathrm{kV}$./cm. was $2 \frac{1}{2}$ times greater when silver was the cathode.

(iv) With proper conditioning the consistency of the results was very noticeable, provided the test electrodes remained in the closed system during the tests. In a long test the initial curves could be reproduced at the end of the test; but the purity conditions appeared to be so exacting that slightly different curves were obtained after a rest period of $12 \mathrm{hr}$.

The impression has been gained that the conductivity may be largely determined by adsorbed layers on the electrodes and hence depends upon the state of purity of the liquid; the two would be expected to be related, and a dynamical equilibrium would be established between them.

It is intended to publish a more detailed account of this work elsowhere.

High Voltage Laboratory,

H. House

Queen Mary College,

London, E.1. May 6.

\section{A New Thermal Method for Sound Absorption in Liquids}

After establishing ${ }^{1}$ the equivalence of sonic and thermal energies (given by the relation $I=J H$, where $I$ is the intensity of sound at the source, $H$ is the heat produced by absorption of this sound and $J$ the conversion factor which has the same value of $4.19 \times 10^{2} \mathrm{ergs} / \mathrm{sec}$. as the mechanical equivalent of heat) this relationship was utilized in this Laboratory to develop a novel technique for the measurement of ultrasonic absorption coefficient in liquids. It consists of the measurement of heat produced at different points along the path of an ultrasonic beam, and its application in the formula $H=H_{0} \exp (-2 \alpha x)$ where $I$ in the usual formula for attenuation is replaced by $H$ because of the earlier equivalence relation. A series of measurements of absorption coefficient have been taken with this technique and the results have already been reported ${ }^{2}$ elsewhere along with full experimental details. These results have shown that the accuracy of this method is high and the values of absorption coefficient so obtained are in close agreement with those obtained by other methods of measurement.

Recently, Dutta and Samal ${ }^{3}$ have reported in Nature measurements of absorption coefficients using the same principle. According to them, the absorption coefficients of benzene and carbon disulphide are $75 \times 10^{-17} \mathrm{~cm}^{-1}$ sec. $^{2}$ and $115 \times 10^{-17} \mathrm{~cm}^{-1}$ sec. $^{2}$ respectively, as against the values obtained by others

\begin{tabular}{|c|c|c|c|c|}
\hline No. & Liquid & $\begin{array}{l}\text { Observed } \\
\alpha / \nu^{2} \times 10^{17} \\
\mathrm{~cm} . \mathrm{sec}^{-1} \text { sec. } \\
\text { at } 28^{\circ} \mathrm{C} \text {. }\end{array}$ & $\begin{array}{c}\text { Previous results } \\
\alpha / \nu^{2} \times 10^{12} \\
\mathrm{~cm} .^{-1} \text { sec. }^{2}\end{array}$ & References \\
\hline & 1 & 2 & 3 & 4 \\
\hline 1 & Benzene & 816 & $\begin{array}{l}900 \text { at } 20^{\circ}-25^{\circ} \\
906, " 30^{\circ} \\
812, " 30^{\circ}\end{array}$ & $\begin{array}{l}4 \\
5 \\
2\end{array}$ \\
\hline 2 & $m$-Xylene & 89 & $\begin{array}{l}80,27^{\circ} \\
76,30^{\circ}\end{array}$ & $6 \underset{5}{\text { and }} 7$ \\
\hline 3 & $n$-Propyl alcohol & 84 & $\begin{array}{l}77 " 26^{\circ} \\
75, " 22^{\circ}-28^{\circ}\end{array}$ & $\begin{array}{l}8 \\
9\end{array}$ \\
\hline 4 & $n$-Propyl acetate & 138 & $145,30^{\circ}$ & 5 \\
\hline
\end{tabular}

which are about $800 \times 10^{-17} \mathrm{~cm}^{-1}$ sec. $^{2}$ and $7,500 \times$ $10^{-17} \mathrm{~cm}^{-1} \mathrm{sec}^{2}$.

To check on these results we have repeated our experiments at about 5 Mc./sec., utilizing our thermal technique. The results obtained are given in column 3 of Table 1. For comparison, results of earlier measurements are given in column 4. It may be seen from these values that the reproducibility is good.

It may also be noted that these results compare well with values obtained by other methods in this Laboratory, as well as with the commonly accepted values based on the results obtained by other workers using a variety of refined techniques ${ }^{4-8}$. Our thermal technique has also been used by Grossetti ${ }^{10}$, who reports good results in water. For our experiments by this technique we have used a generator capable of delivering 10 watts radio-frequency power but set to a low output to prevent the crystal from giving rise to violent ripples in the liquid. It has been observed that, with correct matching, only a small amount of electrical power is needed for the work. Again, the sound energy is completely absorbed in the cell containing a long column of highly absorbing liquid and no correction is required to be made for sound energy leaving the system. This feature also gives rise to more heat, with the result that the accuracy of measurement is comparatively high in this method.

As against this, the results obtained by Dutta and Samal are in complete disagreement with those obtained by us by the above technique and confirmed by us here, as also with other results by workers using different methods. The deviation is obviously due to some flaws in the method and in interpretation of observations. A detailed paper on this work will be published elsewhere.

\section{S. Parthasarathy \\ M. PANChOLY C. B. TIPNIS}

National Physical Laboratory of India, New Delhi 12. June 14.

1 Parthasarathy, S., Chari, S. S., and Srinivasan, D., Ann. d. Phys., 12, 8 (1953); $J$. Acoust. Soc. Amer., 25, 335 (1953). See Nature 173,110 (1954).

- Parthasarathy, S. Chari S. S., and Mahendroo, P. P.,Z Naturforschung, 8a, 273 (1953): J. de Phys. et le Rad. 14, 366 (1953). Parthagarathy S and Mahendroo P P Il Nuovo Cimento 10. 1196 (1953). Parthasarathy, S., Mahendroo, P. P., and Mathur, S. S., J. Sci. Indust. Res., 12B, 457 (1953).

Dutta, A. K., and Samal, K., Nature, 174, 976 (1954)

4 Markham, J. J., Beyer, R. T., and Lindsay, R. B., Rev. Mod. Phys. 23, 353 (1951)

${ }^{5}$ Parthasarathy, S., Tipnis, C. B., and Pancholy, M., Z. Phys., 140 156 (1955).

' Willard, G. W, J. Acoust. Soc. Amer., 12, 438 (1941).

"Pinkerton, J. M. M., Proc. Phys. Soc., 62B, 129 (1949).

8 Parthasarathy, S., Tipnis, C. B., and Pancholy, M., Z. Phys. (in the press).

- Pellarn, J. R., and Galt, K. J., J. Chem. Phys., 14, 608 (1946).

${ }^{10}$ Grossetti, E., Il Nuovo Cimento, 11, 250 (1954). 